\title{
Evaluation of Self-Directed Learning Readiness among Undergraduate Students in an Indian Physical Therapy Institute
}

\author{
Prachita Walankar ${ }^{1}$, Vrushali Panhale ${ }^{2}$ \\ ${ }^{1}$ Assistant Professor, ${ }^{2}$ Professor; \\ MGM College of Physiotherapy, Sector-30, Vashi, Navi Mumbai-400705, India \\ Corresponding Author: Prachita Walankar
}

\begin{abstract}
Self-directed learning (SDL) is an essential element in medical education to foster lifelong learning. Self-directed learning readiness is the extent to which an individual has the attitude, ability, skill and personality characteristics essential for SDL. This study aimed to analyze self-directed learning readiness among physiotherapy students. A cross-sectional study was conducted among 288 undergraduate physiotherapy students using Self-Rating Scale of Self-Directed Learning (SRSSDL) to assess self-directed learning readiness. Data were analyzed using the Statistical Package for the Social Sciences software version 21. Statistical significance was set at $\mathrm{P}<0.05$. A total 288 participants, $143(49.65 \%)$ were in preclinical phase and $145(50.35 \%)$ in clinical phase. Out of 288 physiotherapy students, $60.76 \%$ students had moderate level, followed by $37.5 \%$ with high level and $1.74 \%$ with low level of SDL readiness. The total SRSSDL score was higher in clinical students as compared to preclinical students using independent $\mathrm{t}$ test $(\mathrm{p}=0.000)$. Also, subscale scores of SRSSDL, awareness $(\mathrm{p}=0.000)$, learning strategies $\quad(\mathrm{p}=0.000)$, learning activities $(\mathrm{p}=0.000)$, evaluation $(\mathrm{p}=0.000)$ and interpersonal skills $(\mathrm{p}=0.04)$ were higher in clinical students as compared to preclinical students using independent $t$ test. The study showed that physiotherapy students had moderate level of SDL readiness. The SDL readiness was found to be higher in clinical students as compared to preclinical. It will assist the medical educators to incorporate more active learning strategies to enhance SDL skills and help in curriculum development.
\end{abstract}

Keywords: Self-directed learning, physical therapists, medical education, students.

\section{INTRODUCTION}

Self-directed learning (SDL) is an essential element of adult education that has been endorsed by varied specialties in medicine. SDL is defined as the process in which the learner takes the initiative, with or without the help of others, establishes their own learning needs, devise learning goals, identify learning resources, choose and execute learning strategies and then evaluate the learning outcomes. ${ }^{[1]}$ In SDL, learner is responsible for his or her own learning with emphasis on autonomy and selfactualization. ${ }^{[2,3]}$ The extent to which an individual has the attitude, ability, skill and personality characteristics essential for SDL is known as self-directed learning readiness. [4] It is an innate attribute present in all individuals. However, the extent of this learning readiness varies from person to person. ${ }^{[5]}$ There is a switch in the learning process from pedagogy to andragogy as the development of an individual occurs. This transition takes place at different timeline for each learner. ${ }^{[6]}$ Physiotherapy education is undergoing a constantly changing environment with students experiencing diverse learning activities. ${ }^{[7]}$ A physical therapy student should acquire knowledge, skills, attitudes and values essential to provide effective patient care. This 
necessitates students to possess self-directed learning skills to pursue lifelong learning. Vast literature and medical knowledge along with complex clinical practice makes self-directed learning imperative for health care personnel to continue professional development throughout the career.

SDL is essential to facilitate independent learning, increase accountability and responsibility with primary aim to enhance lifelong learning. ${ }^{[8]}$ A study conducted in first year Saudi Medical students showed that they had high desire for learning and self-control, yet the self-management skills needed further improvement. ${ }^{[9]}$ A mixed method study evaluated the self-directed learning readiness in 452 Indian medical students across the training years. It showed that there was decline in SDL readiness scores across the batches from admission year to the final year of undergraduate medicine (MBBS) program. ${ }^{[10]}$

There is dearth of literature about self-directed learning readiness in physiotherapy students. Physiotherapists are integral members of the multidisciplinary health-care team. They have to incorporate self-learning skills to continue professional development lifelong. Evaluating the SDL readiness among physical therapy students will assist the academicians to formulate the educational objectives for self-directed learning. Hence, the primary purpose of this study was to evaluate the self-directed learning readiness in physiotherapy students and determine whether self-directed learning readiness differed between preclinical and clinical physiotherapy students.

\section{MATERIALS AND METHODS}

A cross-sectional study was conducted among undergraduate physiotherapy students. Participation in the study was on a voluntary basis, and a declaration of informed consent was obtained from students before participating in the study. All participants were assured confidentiality. A brief explanation about the objective of the study was given to the students and they were asked to complete the questionnaire. The study was approved by the Institutional Research Review Committee.

Physical therapy undergraduate curriculum comprises of a $4 \frac{1}{2}$ year, fulltime program that culminates in a professional qualification and a bachelor of physiotherapy degree. Physiotherapy students in the 1st, 2nd, and 3rd years were categorized as preclinical where the primary focus is on learning fundamental subjects. Clinical students comprise of physiotherapy students in the 4th year and internship. The study population consisted of 143 preclinical (1st, 2nd, and 3rd years) and 145 clinical (final year and intern) physiotherapy students. ${ }^{[11]}$ Demographic information such as age, gender, board of pre-university schooling and current place of stay were noted.

We used Self-Rating Scale of SelfDirected Learning (SRSSDL), developed by Williamson, to evaluate the self-directed learning readiness. ${ }^{[12]}$ The content validity of the tool has been established using Delphi technique in 30 nursing students. Also, the scale reported good internal consistency and construct validity. ${ }^{[12]}$ It comprises of 60 items classified into five subscales. Each subscale consists of 12 items each. The five subscales are awareness, learning strategies, learning activities, evaluation and interpersonal skills. Each item was scored on a five-point Likert type scale: $5=$ always, $4=$ often, $3=$ sometimes, $2=$ seldom, $1=$ never. The total score ranges from 60 to 300 with higher the score showing higher level of SDL. The total score is categorized into three levels indicating SDL readiness: low level (60-140); moderate level (141-220); and high level (221-300). ${ }^{[12]}$

\section{Statistical Methods}

Data were analysed using the Statistical Package for the Social Sciences software version 20.0 (IBM Corporation, Armonk, NY, USA). Descriptive statistics 
were used to describe the demographic characteristics of the students. Mean and standard deviation values were calculated for continuous variables. Categorical variables were reported as proportions and percentages. Independent t-test was used to compare the mean SRSSDL scores and five subscale scores (awareness, learning strategies, learning activities, evaluation and interpersonal skills) between preclinical and clinical students. $\mathrm{P}<0.05$ was considered statistically significant.

\section{RESULTS}

The demographic characteristics of the study participants are shown in Table 1. Of the 288 participants, $143(49.65 \%)$ were in preclinical phase and $145(50.35 \%)$ were in clinical phase.

Table 1: Demographic characteristics of the preclinical and clinical physiotherapy students
\begin{tabular}{|l|c|c|c|}
\hline \multicolumn{1}{|c|}{ Variable } & Preclinical $(\mathbf{n}=\mathbf{1 4 3})$ & Clinical $(\mathbf{n}=\mathbf{1 4 5})$ & Total $(\mathbf{n}=\mathbf{2 8 8})$ \\
\hline Age (in years) [Mean \pm SD] & $19.64 \pm 0.91$ & $21.46 \pm 0.92$ & $20.56 \pm 1.29$ \\
\hline Gender [N (\%)] & $14(9.79 \%)$ & $19(13.1 \%)$ & $33(11.46 \%)$ \\
Male & $129(90.21 \%)$ & $126(86.89 \%)$ & $255(88.54 \%)$ \\
Female &
\end{tabular}

Out of 288 physiotherapy students, $60.76 \%$ students had moderate level of SDL readiness, followed by $37.5 \%$ with high SDL readiness and $1.74 \%$ with low level of SDL readiness. In preclinical students, 96.5\% students had moderate level of SDL readiness and $3.49 \%$ had low level. Whereas among the clinical students, $74.48 \%$ had high level and $25.52 \%$ had moderate level of SDL readiness [Table 2].

It was observed that clinical students had significantly higher mean total SRSSDL scores as compared to preclinical students using independent $t$ test $(p=0.000)$. Also, subscale scores of SRSSDL were compared between preclinical and clinical students using independent $\mathrm{t}$ test. Awareness $(p=0.000)$, learning strategies $(p=0.000)$, learning activities $(\mathrm{p}=0.000)$, evaluation $(\mathrm{p}=0.000)$ and interpersonal skills $(\mathrm{p}=0.04)$ were higher in clinical students as compared to preclinical students using independent $\mathrm{t}$ test [Table 3].

Table 2:Self-directed learning readiness in preclinical and clinical physiotherapy students

\begin{tabular}{|l|c|c|c|}
\hline Self-directed learning readiness & $\begin{array}{c}\text { Preclinical (n=143), } \\
\mathbf{n}(\mathbf{\%})\end{array}$ & $\begin{array}{c}\text { Clinical (n=145), } \\
\mathbf{n}(\mathbf{\%})\end{array}$ & $\begin{array}{c}\text { Total }(\mathbf{n = 2 8 8}), \\
\mathbf{n}(\mathbf{\%})\end{array}$ \\
\hline Low level (60-140) & $5(3.49 \%)$ & $0(0)$ & $5(1.74 \%)$ \\
\hline Moderate level (141-220) & $138(96.5 \%)$ & $37(25.52 \%)$ & $175(60.76 \%)$ \\
\hline High level (221-300) & $0(0)$ & $108(74.48 \%)$ & $108(37.5 \%)$ \\
\hline
\end{tabular}

Table 3: Comparison of mean scores of self-directed learning readiness and subscale scores in preclinical and clinical physiotherapy students using Independent $t$ test.

\begin{tabular}{|l|c|c|c|c|}
\hline $\begin{array}{c}\text { Self-Directed learning } \\
\text { Readiness (SRSSDL) }\end{array}$ & $\begin{array}{c}\text { Preclinical } \\
(\mathbf{n = 1 4 3 )}\end{array}$ & $\begin{array}{c}\text { Clinical } \\
(\mathbf{n = 1 4 5})\end{array}$ & $\mathbf{T}$ & $\begin{array}{c}\text { Independent t test } \\
\text { P value }\end{array}$ \\
\hline SRSSDL Total Score & $164.59 \pm 11.96$ & $232.81 \pm 21.07$ & -33.731 & 0.000 \\
\hline Subscale & & & & \\
\hline Awareness & $29.76 \pm 5.29$ & $46.52 \pm 4.65$ & -27.788 & 0.000 \\
\hline Learning strategies & $29.19 \pm 4.03$ & $46.45 \pm 5.75$ & -29.438 & 0.000 \\
\hline Learning activities & $30.16 \pm 4.49$ & $46.4 \pm 5.66$ & -26.936 & 0.000 \\
\hline Evaluation & $29.59 \pm 4.13$ & $46.04 \pm 5.85$ & -27.509 & 0.000 \\
\hline Interpersonal skills & $45.87 \pm 6.77$ & $47.4 \pm 5.74$ & -2.063 & 0.04 \\
\hline
\end{tabular}

\section{DISCUSSION}

The present study analysed the selfdirected learning readiness among physiotherapy students using Self-Rating Scale of Self-Directed Learning (SRSSDL). Out of 288 physiotherapy students, $60.76 \%$ students had moderate level of self-directed learning readiness. Clinical students had better self-directed learning readiness total score and subscale scores as compared to preclinical students.

A recently published cross-sectional analytical study assessed self-directed learning readiness, using Fishers'40-item self-directed learning readiness scale among 4th semester undergraduate medical 
students of Andhra Medical College, Visakhapatnam, Andhra Pradesh. [13] It showed that $64 \%$ students had low readiness and $36 \%$ had high readiness for SDL. It revealed that SDL skills were low in medical students and required attention. [13] Another study conducted in 272 undergraduate nursing students in Thailand showed that self-directed learning readiness improved with age, maturity, and as students progressed across a course. ${ }^{[14]}$ This is consistent with our study that clinical students who were elder than preclinical students have better SDL skills as compared to preclinical.

Studies have been reported in medical and nursing discipline with respect to self-directed learning readiness. $[15,16]$ Despite the similar framework as for medical and nursing, there have been very less literature about SDL readiness in allied health students. ${ }^{[17]}$ A recent study evaluated self-directed learning readiness in 584 firstyear undergraduate students in health professional programs-health promotion, health services management, therapeutic recreation, sports and exercise science, occupational therapy, physiotherapy, and podiatry. It was observed that SDL readiness was higher in occupational therapy and physiotherapy students. Also, it increased with age and higher levels of previous education. [18] Another recently published cross-sectional study evaluated SDL readiness using 38-item self-directed learning readiness scale in 865 undergraduate health science students including medicine, nursing, physiotherapy and psychology at the University of Girona, Spain. It showed that nursing undergraduates had highest SDL readiness compared to other speciality students. ${ }^{[19]}$

Physical therapy practice requires selfdetermined, professional clinical decision making and critical thinking process. [20] Physical therapy students need to acquire skills such as confidence, autonomy, motivation and preparation for lifelong learning. [21] Physiotherapy curriculum comprises of preclinical and clinical phase.
In preclinical program, major focus is on obtaining basic knowledge of medical sciences. [22] Didactic-based classroom lectures are the common teaching method advocated in this phase. It is more teacheroriented program with less active participation from the students. However, clinical students adopt active and independent approach towards learning. Problem based learning, case-based teaching, tutorials and community-based teachings are the major methods employed during this phase. There is an integration of knowledge acquired during the preclinical phase which is applied in the clinical phase. [23] Incorporation of these methods of learning enhances the critical thinking and makes the learner accountable for his own learning. [24] A cross-sectional study conducted in 536 Chinese nursing students revealed that $62.3 \%$ had high level, and $37.7 \%$ low level of SDL readiness. It also reported that students in higher academic years scored higher on self-directed learning readiness due to increased maturity. ${ }^{[25]}$ This is consistent with our study that clinical students had better SDL readiness as compared to preclinical physiotherapy students.

Self-directed learning brings about active learning so that the learner attains indepth knowledge and understanding of a concept rather than rote learning. It leads to active participation of student and makes him or her responsible for his own learning leading to positive motivation. ${ }^{[26]} \mathrm{SDL}$ is evolving in medical education and is influenced by multiple elements like personality characteristics of the learner, management of learning skills, learning environment, and metacognitive process. ${ }^{[27}$, 28]

Our study reveals that preclinical students need further boost for SDL to take more control of their learning process due to the vast curriculum. Incorporation of varies strategies like problem-based learning, innovative teaching, group discussions and tutorials can be added in the curricula to enhance the SDL skills and provide deeper 
understanding of the concept. [15,24,29] Understanding the SDL readiness is a precursor to SDL. Assessment of selfdirected learning readiness will assist the medical educators to implement appropriate teaching strategies to enhance SDL skills and help in curriculum development. ${ }^{[15]}$

The strength of the study was that it is a primary study to assess the SDL readiness among the clinical and preclinical physiotherapy students. However, there are few limitations of this study. The current study utilized a self-report questionnaire which was based on student's perceptions and not a direct quantification of SDL readiness. Also, it was conducted in only one institution which may affect the generalization of findings. As a crosssectional study design was incorporated, we were able to draw conclusions at a single time point only. Future studies can be conducted in multicentre cohorts. We recommend future researchers should conduct longitudinal studies with following students throughout the academic year or across years to determine SDL skills over time.

\section{CONCLUSION}

This study provided baseline data regarding the SDL readiness of undergraduate physiotherapy students with $60.76 \%$ students having moderate level of SDL readiness. It was observed that clinical students had better self-directed learning readiness as compared to preclinical physiotherapy students. Academicians should incorporate more independent and active learning strategies like problem-based learning to enhance SDL skills in students.

Acknowledgement: The authors would like to thank all the students who participated in the study.

\section{Support: Nil}

\section{Conflict of Interest: None}

Source of Funding: None

Ethical Approval: Approved

\section{REFERENCES}

1. Knowles MS. Self-directed learning: a guide for learners and teachers. NewYork: Associated Press; 1975.

2. Premkumar K, Pahwa P, Banerjee A, Baptiste K, Bhatt H, Lim HJ. Does medical training promote or deter self-directed learning? A longitudinal mixed-methods study. Acad Med. 2013 Nov; 88(11):175464.

3. Kaufmann DM, Mann KV, Jennett PA. Teaching and learning in medical education: How theory can inform practice. Edinburgh: Association for the Study of Medical Education; 2000.

4. Wiley K. Effects of a self-directed learning project and preference for structure on selfdirected learning readiness. Nursing Research. 1983; 32(3):181-85.

5. Fisher M, King J, Tague G. Development of a self-directed learning readiness scale for nursing education. Nurse Educ Today. 2001 Oct; 21(7):516-25.

6. Merriam, S. Andragogy and self-directed learning: Pillars of adult learning theory. New Directions for Adult and Continuing Education. 2001; 89, 3-13.

7. Walankar P, Panhale V, Situt S. Students' Perception of the Educational Environment in an Indian Physiotherapy College. The Internet Journal of Allied Health Sciences and Practice. 2019 Mar 26; 17(2).

8. Gyawali S, Jauhari AC, Ravi Shankar P, Saha A, Ahmad M. Readiness for selfdirected learning among first semester students of a medical school in Nepal.J Clin Diagnostic Res. 2011;5:20-3.

9. Soliman M, Al-Shaikh G. Readiness for Self-Directed learning among first year Saudi Medical students: A descriptive study. Pak J Med Sci. 2015; 31(4):799-802.

10. Premkumar, K., Vinod, E., Sathishkumar, S. et al. Self-directed learning readiness of Indian medical students: a mixed method study. BMC Med Educ 18, 134 (2018).

11. Walankar PP, Panhale VP, Situt SA. Evaluation of learning approaches in physiotherapy students: A valuable insight. J Educ Health Promot. 2019;8:25. Published 2019 Feb 15

12. Williamson SN. Development of a selfrating scale of self-directed learning. Nurse Res. 2007;14(2):66-83.

13. Madhavi KVP, Madhavi BD. Readiness for self-directed learning among undergraduate 
medical students of Andhra Medical College, Visakhapatnam. Int J Community Med Public Health 2017;4:2836-40.

14. Klunklin A, Viseskul N, Sripusanapan A, Turale S. Readiness for self-directed learning among nursing students in Thailand. Nurs Health Sci. 2010 Jun;12 (2): 177-81.

15. Abraham RR, Fisher M, Kamath A, Izzati TA, Nabila S, Atikah NN. Exploring firstyear undergraduate medical students' selfdirected learning readiness to physiology. Adv Physiol Educ. 2011 Dec;35(4):393-5.

16. Monroe, K. S. The relationship between assessment methods and self-directed learning readiness in medical education. International Journal of Medical Education. 2016; 7, 75-80. 5-80.

17. Linares AZ. Learning styles of students and faculty in selected health care professions. $J$ Nurs Educ. 1999 Dec;38(9):407-14

18. Slater CE, Cusick A, Louie JCY. Explaining variance in self-directed learning readiness of first year students in health professional programs. BMC Med Educ. 2017 Nov 13;17(1):207.

19. Rascón-Hernán C, Fullana-Noell J, FuentesPumarola C, Romero-Collado A, Vila-Vidal D, Ballester-Ferrando D. Measuring selfdirected learning readiness in health science undergraduates: A cross-sectional study. Nurse Educ Today. 2019;83:104201.

20. American Physical Therapy Association. Vision 2020. 2013. Accessed online:www.apta.org/vision2020. 2013.

21. Jacobs JL, Samarasekera DD, Shen L, Rajendran K, Hooi SC. Encouraging an environment to nurture lifelong learning: an Asian experience. Med Teach. 2014 Feb;36 (2):164-8.

22. Bitran M, Zúñiga D, Pedrals N, Padilla O, Mena B. Medical students' change in learning styles during the course of the undergraduate program: from 'thinking and watching' to 'thinking and doing'. Can Med Educ J. 2012 Sep 30;3(2):e86-97.

23. Samarakoon L, Fernando T, Rodrigo C. Learning styles and approaches to learning among medical undergraduates and postgraduates. BMC Med Educ. 2013 Mar 25;13:42.

24. Dubey S, Dubey AK. Promotion of higher order of cognition in undergraduate medical students using case-based approach. J Educ Health Promot. 2017 Aug 9;6:75.

25. Bin YH, Williams BA, Fang JB, Pang D. Chinese baccalaureate nursing students' readiness for self-directed learning. Nurse Educ Today. 2012; 32:427-31.

26. Dent J, Harden RM. A practical guide for medical teachers. London: Elsevier Health Sciences; 2013.

27. Murad MH, Varkey P. Self-directed learning in health professions education. Ann Acad Med Singap. 2008 Jul;37(7):58090.

28. Morris TH. Self-directed learning: A fundamental competence in a rapidly changing world. Int Rev Educ. 2019; 65(4):633-653.

29. Saurabh MK, Agrawal J. The opinion of undergraduate medical students on current curriculum and teaching methodology of pharmacology in four medical colleges of India: a questionnaire based study. Int J Basic Clin Pharmacol. 2015; 4:970-5.

How to cite this article: Walankar P, Panhale V. Evaluation of self-directed learning readiness among undergraduate students in an Indian Physical Therapy Institute. International Journal of Science \& Healthcare Research. 2021; 6(3): 1-6. DOI: https://doi.org/10.52403/ ijshr.20210701 